\title{
INTERVIEW
}

\section{Touching Sound: An Interview with Jayne Parker by Aura Satz}

ayne Parker was born in Nottingham in 1957. She studied at Mansfield College of Art,
Canterbury College of Art, and the Slade. She was a visiting lecturer at Goldsmiths College
from 1984 until 1998 and has taught at the Slade School of Fine Art since 1989, where she is now Head of Graduate Fine Art Media. There is a strong element of performance in all of Jayne's work, articulated through the body - the musician, the dancer, the performer. Most of her recent work features the performance of music. Jayne uses the materiality and precision of film to convey a sense of space within the frame, to make connections between seemingly unconnected images and events, and, as she writes, "to try to see and feel what a body can do." Her work has been shown at art venues, on television, and in film festivals internationally. In October 2011, during "Maya Deren: 50 Years On" at the British Film Institute in London," Jayne's films were presented and discussed as part of a season of events exploring the significance of Deren's legacy to contemporary British women's practice.

Artist and writer Aura Satz first encountered Jayne Parker when she was a PhD student at the Slade between 1998-2002. Jayne's work provided many resonances for Aura's later work with sound, musicians, and musical gesture, and both artists have collaborated extensively with cellist Anton Lukoszevieze. In June 2012 Aura included Jayne's work in a curated screening at a pop-up cinema at Christies, South Kensington London, UK as part of Exhibition Road's event "Supersonix."2 The films shared an attention and sensitivity to the materiality of sound and sound-making technologies, devices, and instruments. Alongside her own films, and Jayne's, Aura screened films by Manon de Boer and Luke Fowler.

Jayne's recent Trilogy: Kettles Yard (2008), a series of films featuring Lukoszevieze, are documents of the performances of three compositions for cello. Each composition prescribes an intriguing mediation in the encounter between body and instrument: the tapping of strings with the left hand, the voicing of phonemes, the improvisation of gesture. Set at Kettles Yard, the University of Cambridge gallery house, Trilogy also includes art objects, which open up the metaphorical space and meaning of the compositions. In this interview Jayne reflects on her filmic approach to the performance of sound, the choreography of musical expression and the sculptural quality of the played instrument.

Aura Satz: As this issue of the Journal is focused on the continued relevance of Maya Deren's art and influence, can I begin by asking when you first encountered her films? Like Deren you have collaborated with dance performers, and constructed choreographies for camera; I wonder how her treatment of dance movement on film resonates with your own. 
Jayne Parker: The first Maya Deren film I saw was Meshes of the Afternoon (1943). I can't remember when or where saw it but it was after I had left the Slade. Perhaps it was at the London Film Maker's Co-op or the NFT. I remember liking At Land (1944), especially the part when Deren is climbing the tree bole from the beach to the dining table.

When I think of Maya Deren I always see her as she is in her films: straight back, totally present, striding out, or with a curious knowing expression-and that wonderful hair. I see her as a force of nature, indefatigable, a beacon, whose visionary films endure-memorable, unforgettable-but most of all I am struck by how she articulates filmic space, crossing the boundaries and limitations of our everyday perception.

I value Deren's film presence as a performer and a dancer and the fervour of her relentless drive. I am not a dancer myself but have been drawn to dance. I long to be inside the movement and have access to such physical expression. I particularly like the extreme nature of ballet and its symbolic language, which can be deeply shocking. I approach filming dance in much the same way as other performance subjects. I tend to like action to happen in front of the camera, for the camera to be static, which is challenging when filming dance. I don't have a sense of how to construct choreographed movement but only of how certain movements makes me feel. I structure film very much in response to what I see and feel. This is true for all my work.

AS: Your work has often involved performative acts captured on film, and clearly your work with both dance and music fits within this context. I wonder whether you could provide a brief overview of how you first came to work with musicians? Am I correct in assuming that the first of these was Crystal Aquarium (1995), which featured a drummer?

JP: Music has always been important in my work. The first film I made which featured a musician was Cold Jazz (1993) when I filmed saxophonist Kathy Stobart. The proposal for this film came about in a roundabout way. I was on holiday in France and went to a jazz evening. There was a young saxophonist in the band and she never knew when to come in. She shifted her weight from foot to foot as she counted and the band would circle round until she made it in - then she played perfectly. It reminded me of how I felt when I was making The Pool (1991) and diving into the water-I never knew how to leave the side, how to launch myself into the dive. I was introduced to Kathy through a colleague at work - Kathy was her aunt. Incidentally Debussy referred to the saxophone as "that aquatic instrument" and at the time I thought about the saxophone as being like a metallic eel with the pads opening and closing like gills_-also referring back to imagery in The Pool. All the musicians I have filmed-Kathy Stobart, Michelle Drees, the drummer in Crystal Aquarium (1995), and Katharina Wolpe and Anton Lukoszevieze with whom I have made several films - I have wanted to film because of the quality of their musicianship, their concentration and performance.

AS: Your films reveal an attention to the bodily, choreographic quality of musical performance, and an intense engagement with the materiality of the musical instrument. Can you perhaps explain this specific mode of filmic approach?

JP: I would like to be where the musician is when they are playing-both physically and in their feeling - I want to see and feel what they feel. The question "where is music expressed?" is always there. Is it in the act of playing, the act of touch? Is it in the sound or 
expressed in the face? There is something vicarious about this. Music is a difficult area for me. I nearly did music when I left school but in the end chose art. I always felt I failed at music, that I didn't have a good ear. I had a cello teacher who would become angry when I got something wrong and it made me tentative-I didn't rise to the occasion. So there is a longing for music and a pushing away at the same time. I think of the instrument as standing in for the body, it has a voice and expression - it is the site of music. However, the sense of touch is probably the most important thing.

AS: Some years ago we discussed your film with the eviscerated cello, and I remember you mentioned how much you hated practising. There's a kind of implicit violence in some of the films, whether this be in the destruction of an instrument or, as in one of the films featuring Anton Lukoszevieze, an instrument, which is aggressively scratched, and bears the scars of past performances. What has your relationship to music and your own experience been, and how has this found expression through filmmaking?

JP: I mentioned earlier my relationship to music. I can't remember saying I hated practicing but if I did it would have been because I felt I could never get it right. I certainly never practiced as much as I should have done! I was quick to pick up the basics of playing an instrument and dexterous too, but there comes a point when this isn't enough to carry you through and disciplined practice is required. I always wanted to be better than I was. You are right about the implicit violence in my films. However, in the "music films" it is the score that directs the apparent violence, in that the musician's gestures come about purely through following the composer's notation and this is what fascinates me.

AS: There are a number of musicians who you have worked with on an ongoing basis over several years, such as pianist Katharina Wolpe and the cellist Anton Lukoszevieze. How did those working relationships begin and how did they evolve?

JP: I met Katharina through mutual friends, including the artist Tess Jaray. I knew that I wanted to make a film with Katharina when I heard her give a recital of her father Stefan Wolpe's music at the ICA in the early 1990s_ 1992? The first film we made together, Thinking Twice (1997), was shown at Camden Arts Centre where I met composer Michael Parsons at the opening and he told me about Anton. Anton saw my film and I went to see Anton perform at Kings College and we knew we wanted to work together. Shortly afterwards I was invited to make work for Spacex Gallery, Exeter who co-commissioned the series Foxfire Eins (2000) a series of four films made with Anton, with Film and Video Umbrella. Both Katharina and Anton are important people in my life, great friends and artists, whom I hold in great respect.

AS: Anton features in the trilogy of films you produced for Kettle's Yard, which also engage with sculptural objects in the collection. There is a beautiful sense of poetic resonance between the objects and the musical performance, as well as the parallel camerawork, featuring unusual compositions and unexpected angles. How did you go about devising these works? According to what structuring principles did you choose the artworks and the musical compositions?

JP: The musical compositions featured in Trilogy: Kettle's Yard were pieces that I had wanted to film Anton playing for several years, ever since making Foxfire Eins. Anton was New Music 
Fellow at King's College, Cambridge and Kettle's Yard Gallery from 2005-7, which presented an opportunity for us to film there. Michael Harrison was the Director at this time and he was very supportive and kindly let us film in both the house and the gallery. Originally I had intended to include more objects from the collection but, as often happens, what looks wonderful with the eye doesn't translate through the camera lens, so I only used very few objects whose resonance with the music was apparent. As to the structuring of the films: following the linearity of the score there is already direction, and structure occurs through looking at the form of the music. I try to find ways to approach both the filming and editing that mirrors the sensibility of the musical compositions. Editing Sylvano Bussotti's music, Sensitivo, per arco solo (1959) from the central section of Trilogy: Kettle's Yard, which is a graphic score, proved challenging. I thought at first that I could play a part in determining this indeterminate music through editing, but in the end each take felt complete and I didn't want to interrupt that. So here the takes are long — there is no need to edit. Working with music has changed the frequency of my edits. What in the music or performance is going to indicate a change of view? It could be the meter or the phrasing, but the rhythm of the music doesn't always align with the rhythm of the film.

AS: Your solo exhibition at ROOM in 2009 included sculptures alongside the films. ${ }^{3}$ These included beautiful dismantled and reassembled cello parts which seemed to evoke a darker side to the music. The strings of the bow were loosened to bring back the more animal but also possibly cruel side of musical instrument design. It also recalls the very unusual shape of the curved bow which Anton uses in one of the films, which can play up to four strings at once, producing wonderful chords and harmonics. Again, when at rest it resembles an uncanny horses mane, a relic of sorts, which is both wild and extremely contained. How did these sculptures come about, and how do they relate to your filmmaking?

JP: I think of the sculptures as extending the imagery in the films-I don't experience musical instruments as cruel. I am however interested in the animal in relation to musical instruments, both literally and symbolically. Making objects offers me a chance to explore imagery in a different way and to make explicit connections and references that are often buried in the films. I aim to create objects that are like facetted still moments in that they draw together several things in one image that is actual, physical and tactile. They bring out the physicality of the materials of the instrument and make the instrument more of a body.

AS: Often in your films the choice of music is quite difficult listening, or challenging for the musician. Can you say some more about this stylistic choice, and how you compose the films around such musical compositions and performances?

JP: I choose music that affects me, either aurally or visually, that creates a personal resonance in some way. The pieces of music come about in a variety of ways but most usually through having seen them performed. I like to see music performed; it helps me to hear it_-if I see it I hear it_-seeing and hearing are entwined. I am particularly drawn to the music of Stefan Wolpe. There is something absolute about Wolpe's music, dense and exhilarating and difficult for both performer and listener. It demands concentration. My choice of music is also based on the performative action of the musician-some compositions demand less conventional modes of playing and I am entranced by imagery that comes about through the act of interpreting/translating the score into sound. The cello is a very 

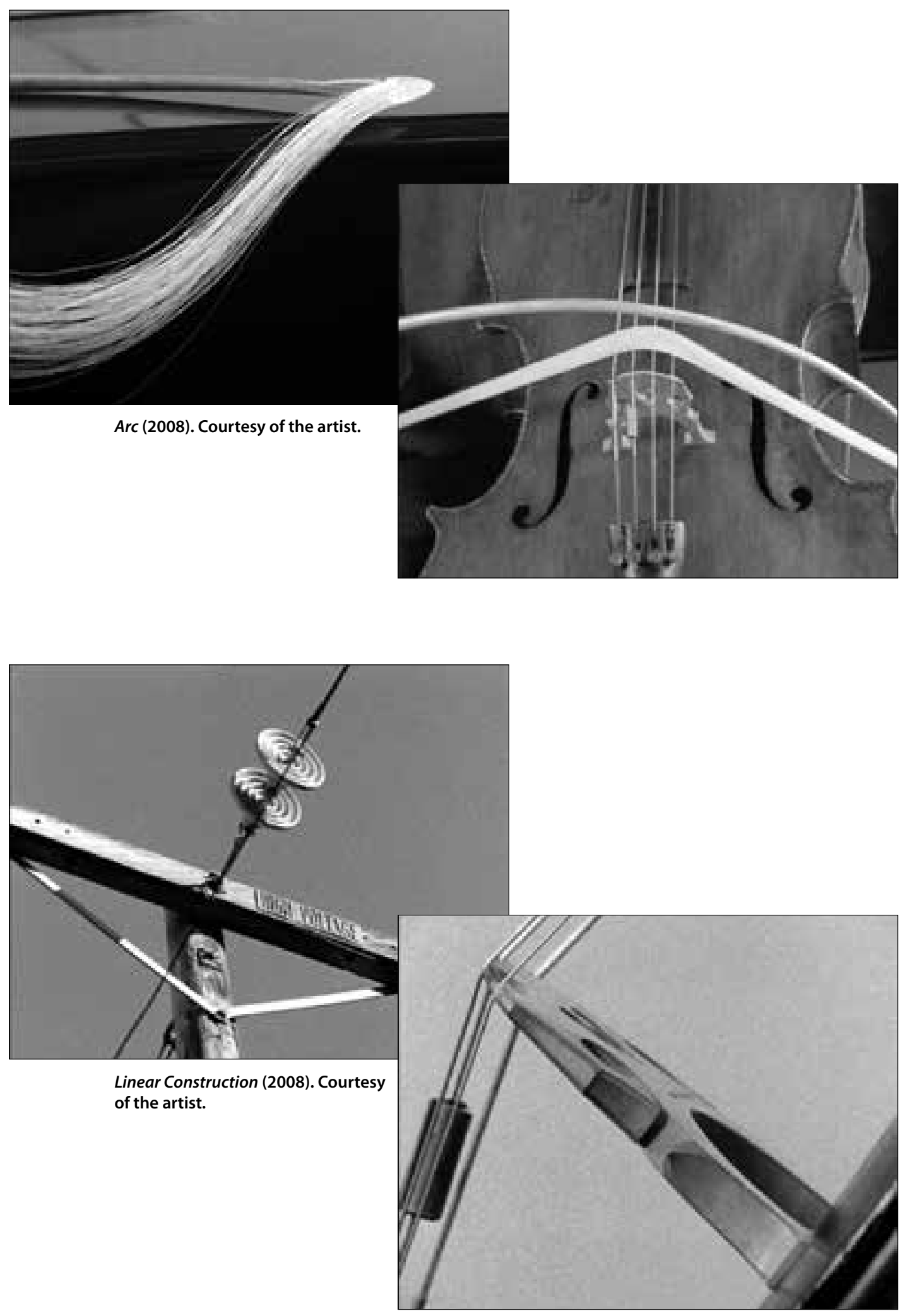


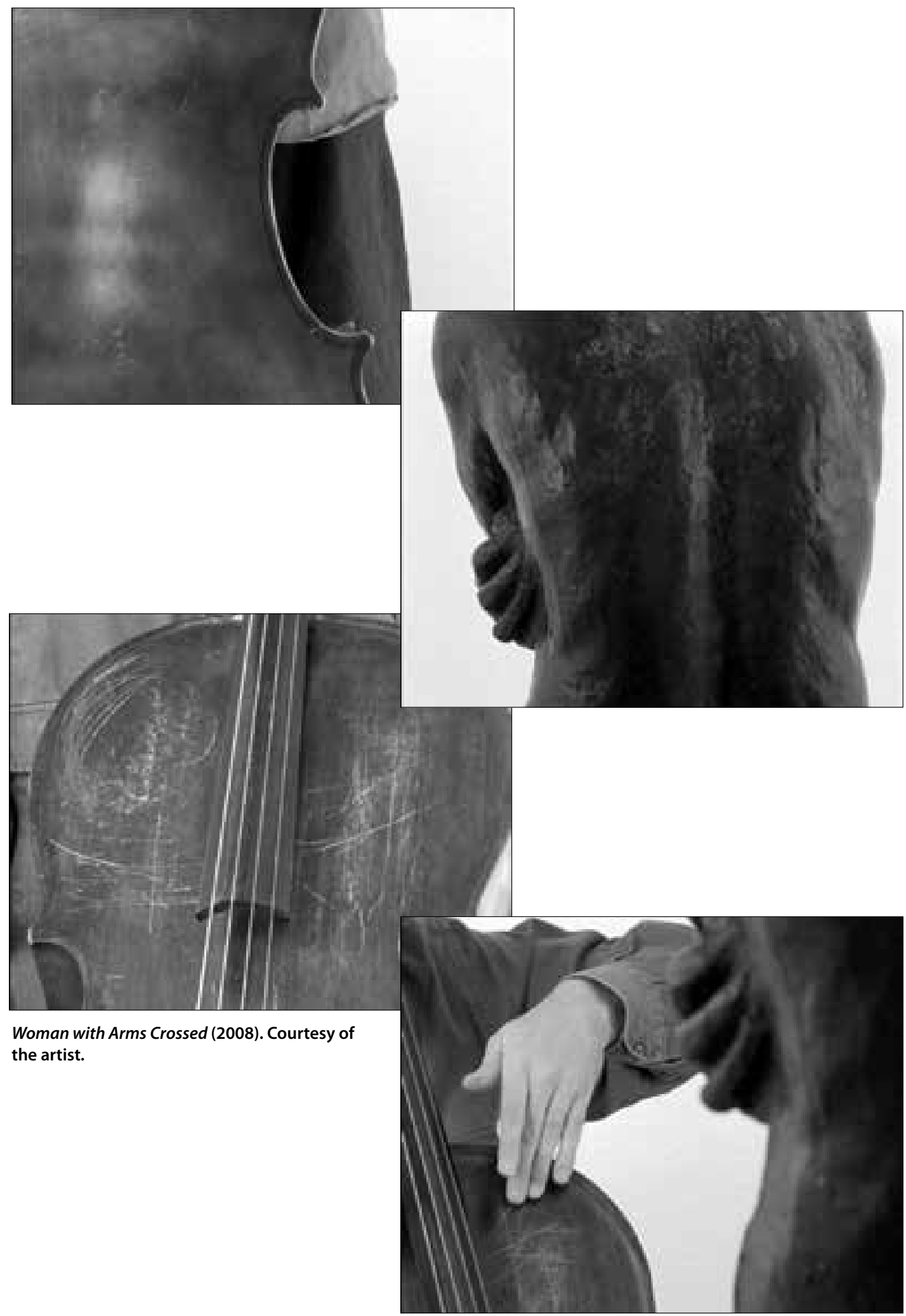


frontally exposed instrument; everything faces outwards with the musician behind. With the piano there is more of an equilibrium - the notes all at rest, settled, like water finding its level - this is how pieces start and end with the piano. With the cello, there is no mechanical interface between the player and the tension of the strings. The action of the piano is internal whilst that of the cello is external. I should say that it is the quality of the performers that is paramount. Both Katharina Wolpe and Anton Lukozsevieze are consummate musicians and the films rest on their very special qualities.

AS: I am always fascinated by the tactile relationship between a musician and his/her instrument, the implied ergonomics of instrument design, and how this prescribes a series of choreographic possibilities, as well as modes of subversion. I find this very interesting from a filmic point of view, as one can guide the viewer to look and, as a result, also hear very differently. How do you structure your camerawork accordingly, and is this something your "score" in advance so to speak?

JP: All the filming is carefully planned to best reflect the music and its structure and catch the nuances of the performer. I only use one camera. From my experience, the second camera always needs to be where the first one is and if you make a mistake you make it twice. It is interesting how consistent musicians can be physically-not just in terms of playing the notes but in how tension and felt experience registers in their bodily movement and expression. I am aware of the structure of the music and keep this in mind in terms of phrasing and my shooting script, where to pick up a shot or end it. I am mindful of how physically demanding performing in a filming situation can be. I aim to make sure everything is covered so I have choice when I am editing, which is where the real structuring takes place.

AS: Can you say something about your relationship to the tactility of $16 \mathrm{~mm}$, and how the medium itself informs the quality of the work?

JP: I can be very pragmatic. I like things to be what they are and film is wonderful for this. It is the materiality and physicality of film is that keeps me working with this analogue medium. It is also what I am used to using. Over the years the medium has shaped how I think, how I see images and how I order material. The 4:3 ratio is ingrained. I like all the stages of filmmaking: loading the camera, framing, shooting, editing. Wanting to film something comes with a sense of urgency — I have to film it. Alongside is anxiety — what if I miss it? With film there is always the possibility of something being more that I could have imagined - it can of course go the other way. It is a transformative process. I like the logic of film, its exacting nature and the precision of the editing process, the depth of space within the frame, filmic space within the frame, the sense of order and all the delineated stages of filmmaking. Film has the stability of a material object. I see a correlation between the grain of the celluloid and the vibration of the sound. I still edit on film and this dictates the decisions and structuring of both the film and my working process.

AS: As an artist, I find myself continually attracted to sound and music as they seem to offer ways of disorienting perception, seeding a sense of doubt as to the source of sound, which is so easily disembodied, and, through film, enabling a potent opportunity to both detach and re-align sound and image, forcing the senses to engage in a closer mode of attention 
and decipherment. What is it about music which draws you in and has made you return to it over and over in so many films?

JP: Music has always been important for its expressive power and its capacity to move us. There was a time when I wanted to make a shift. I felt I was making the same film again and again and I wanted to move the subject away from myself. The films could be seen purely as documents of musical performance but the underlying themes remain the same: the body, inside/outside, felt experience, the body in relation to an object, the object as body, seeking ways to express those things that can't be articulated in any other way, metaphysical yearning.

\section{Media}

Cold Jazz (1993). Dir. Jayne Parker. 16mm, b/w, 17:00 min.

Crystal Aquarium (1995). Dir. Jayne Parker. 16mm, b/w, 33:00 min.

Foxfire Eins (2000). Dir. Jayne Parker. Digibeta from original 16mm, b/w, 10:00 min.

I Dish (1982). Dir. Jayne Parker. 16mm, b/w, 16:00 min.

K(1989). Dir. Jayne Parker. 16mm, b/w, 13:00 min.

The Pool (1991). Dir. Jayne Parker. 16mm, b/w, 10:00 min.

The Reunion (1997). Dir. Jayne Parker. 16mm, colour, 9:00 min, Dance for Camera ACE/BBC.

Stationary Music (2005). Dir. Jayne Parker. Digibeta from original $16 \mathrm{~mm}, \mathrm{~b} / \mathrm{w}, 15: 00 \mathrm{~min}$.

Thinking Twice (1997). Dir. Jayne Parker. 16mm, b/w, 10:00 min.

Trilogy: Kettle's Yard: Linear Construction-Woman with Arms Crossed-Arc (2008). Dir. Jayne Parker. Digibeta from original 16mm, b/w \& colour, 25:00 min.

\section{Notes}

1. Jayne Parker's films I Dish (1982), The Pool (1991), The Reunion (1997), Stationery Music (2005), Arc (2008) and K (1989) were screened at British Film Institute, London Southbank on 7 October 2011 as part of "Maya Deren: 50 Years On."This retrospective was followed by a conversation between the artist and William Fowler, Curator at the BFI National Archive. See http://www.bfi.org.uk/sites/bfi.org.uk/files/downloads/bfi-press-release-bfi-southbankpresents-Maya-deren-50-years-on-2011-08-25.pdf. Jayne Parker's films are distributed by LUX Artists'Moving Image, London, UK. http://www.luxonline.org.uk/artists/jayne_parker/index.html.

2. "Supersonix," a conference and series of events celebrating the art and science of sound, was organised by the Exhibition Road Group, and held in London between 21-23 June 2012. Aura Satz's curated film programme at the Pop Up Cinema, Christie's South Kensington, was screened on 23 June. See http://www.exhibitionroad. com/7416/pop-up-cinema-at-christies-south-kensington-aura-Satz

3. Jayne Parker's solo exhibition at ROOM, an art space on Manchester Street in central London, ran from 15 January - 8 February 2009. Linear Construction, Woman with Arms Crossed, and Arc (collectively Trilogy: Kettles Yard) were presented alongside a small installation of sculptural objects. See http://www.roomartspace.co.uk/ past_detail.php?eventID=133\&eventType=exhibition\&theartist=JAYNE\%20PARKER 